\title{
La invención del arquitecto
}

\section{Enrique Bonilla Di Tolla}

Universidad de Lima, Perú

Recibido: 12 de mayo de 2014 / Aprobado: 7 de julio de 2014

A pesar de que la arquitectura ha existido desde siempre, no sucede lo mismo con los arquitectos. Hay antecedentes de su existencia sobre todo en la antigüedad grecorromana, pero desaparecen en la Edad Media. En el Renacimiento, la arquitectura es definida como una disciplina artística y científica. Además, se inventa al arquitecto - a partir de una visión platónica - como demiurgo o hacedor. El primer escrito que habla de arquitectura y arquitectos es obra de Vitruvio, pero es con León Battista Alberti, figura significativa dentro de la invención del arquitecto, que se especifica la importancia de la arquitectura y los arquitectos dentro de la construcción del hecho cultural humano.

arquitectura, humanismo, Renacimiento, arquitecto, disciplina

\section{The invention of the architect}

Although architecture has always existed, architects have not.There are records of architects, especially from greco-roman antiquity, but they disappear into the Middle Ages. During the renaissance, architecture is defined as an artistic and scientific discipline. In addition to that, the architect was invented -in a platonic view - as demiurge or maker of architecture itself. The first text that talks about architecture and architects is the work of Vitruvius, but with Leon Battista Alberti, significant figure within the creation of the architect, that the importance of architecture and architects is specified within the construct of the human culture.

architecture, humanism, Renaissance, architect, discipline 
La arquitectura como hecho cultural - en el sentido amplio de la palabra que se refiere a toda manifestación humana- existió desde que el hombre decidió edificar su primera morada. Quizá la cabaña primitiva — como lo sostenía Laugier- fue el primer hecho arquitectónico, que respondiendo a la necesidad de cobijo, inició un proceso de transformación del medio natural para adaptarla a las necesidades humanas. Si bien está claro que siempre existió la arquitectura, también está claro que no siempre existieron los arquitectos.

Tal vez el propio nombre de 'arquitecto' haya tenido su origen en la Grecia clásica, donde la unión de los vocablos archi (persona con autoridad o conocimiento) y tekton (construcción) sea el origen del arquitecto. En el siglo I a.C., Vitruvio (Marcus Vitruvius Pollion), en el único manuscrito sobre el tema que se conserva de la antigüedad romana, se define como tal, e incluso nos habla ya de arquitectura y de arquitectos, muchos de ellos figuran en sus proemios o introducciones a cada uno de sus libros (capítulos) del tratado De arquitectura o Los diez libros de la arquitectura, como se le denomina indistintamente a este importante texto.

Sin embargo, esta tradición del arquitecto no continuó más allá de la antigüedad clásica. En la Edad Media, época en que, como es sabido, hubo arquitectura — paleocristiana, bizantina, románica, y especialmente un esplendoroso gótico- lo que no hubo fueron arquitectos. La obra de arquitectura fue el resultado de un trabajo colectivo de diversos artesanos (canteros, carpinteros, herreros, vitralistas, etcétera) al mando probablemente de un maestro experimentado, pero que mantuvo siempre su condición de artesano. Es claro, sobre todo durante la construcción de las grandes iglesias góticas, que la obra era también un lugar de aprendizaje, donde los artesanos enseñaban a los jóvenes aprendices el manejo de un determinado oficio y que este se complementaba después de la jornada en las "logias", un aposento especialmente adecuado para dar charlas sobre el manejo correcto de los materiales, los procedimientos de construcción o el uso correcto del compás y de la regla.

Esta situación cambia sustantivamente durante el Renacimiento, cuando la figura del arquitecto reaparece de la mano de un personaje central que se encargaría de dos cosas: de elevar la arquitectura a la categoría de arte mayor; 
y de definir al arquitecto como el autor-artista que la produce. Este personaje fue León Battista Alberti ${ }^{1}$.

Antes de Alberti el ejercicio de la arquitectura no era considerado un arte. Por entonces las denominadas "artes liberales" estaban constituidas por la geometría, la música y la poética o retórica. Corresponderá a Alberti, a partir de sus tratados De pictura, De estatua y De reaedificatoria, incorporar a la pintura, la escultura y la arquitectura al universo de las artes. Para ello tuvo que reconstruir, de alguna manera, el sentido que tuvo la arquitectura en la antigüedad, a partir el texto de Vitruvio, que fue el único documento parcialmente conservado de la arquitectura romana al cual tuvo acceso, y que muchos consideramos fundacional de la arquitectura, al que sin embargo Alberti encuentra algunos reparos:

En efecto, me causaba pesar que los testimonios tan abundantes y tan señalados, de los escritores se hubieran perdido por la adversidad de las circunstancias y de los hombres, de tal modo que teníamos como que apenas teníamos [sic] como sólo superviviente de un naufragio de tal magnitud a Vitruvio, autor muy competente sin duda alguna, pero tan golpeado y castigado por el paso del tiempo que en multitud de pasajes faltan muchas cosas y en muchos otros echas en falta bastantes más (Alberti, 1550, p. 243).

Por ello, para la construcción de la arquitectura como disciplina Alberti echará mano a otros documentos de varios autores, que le permitirán esbozar el concepto de arquitecto que pretende establecer:

A la hora de pasar revista a los elementos que son útiles para la construcción de edificios, vamos a recoger lo que nos han transmitido autores antiguos documentados al respecto, sobre todo Teofrasto, Aristóteles, Catón, Varrón, Plinio y Vitruvio —en efecto, estos conocimientos se obtienen más de una dilatada experiencia que por el cultivo de una disciplina intelectual- de modo que ha de ser extraída esta información de quienes la han registrado con enorme laboriosidad (Alberti, 1550, p. 100).

1 León Battista Alberti (Génova, Italia, 18 de febrero de 1404 - Roma, 20 de abril de 1472) fue sacerdote, secretario personal (abreviador apostólico) de tres papas (Eugenio IV, Nicolás V y Pío II) (desde 1431 a 1464), humanista, arquitecto — proyectó edificios, aunque nunca dirigió sus obras - matemático y poeta italiano. Además de estas actividades principales, también fue criptógrafo, lingüista, filósofo, músico y arqueólogo. Es una de las figuras del humanismo y de las personalidades artísticas y teóricas más polifacéticas del Renacimiento. 
Debemos decir, además, que Alberti era un humanista con una sólida formación. Su holgada posición económica y social le había permitido tomar clases de latín, retórica antigua, filosofia y poética con Gasparino Barziza, uno de los principales estudiosos de Cicerón en su época, para posteriormente acudir a la Universidad de Bolonia, donde cursó estudios en filología, retórica y filosofia, además de matemáticas y fisica, aunque al final decidiera graduarse en derecho canónico y civil (Biermann, 2003, p. 22).

Su interés por la arquitectura nacería después, cuando en ejercicio de su trabajo para el papado, llegara a Florencia, en la tercera década del siglo XV. Este será no solo un grato encuentro con la ciudad natal de su padre y de su familia -él había nacido en Génova debido al exilio de su progenitorsino que en Florencia quedó maravillado por el despliegue de talento que desarrollaban artistas como Donatello, Ghiberti, Della Robbia, Brunelleschi, entre otros, trabando con este último una gran amistad y a quien dedica la versión en volgare (italiano) de su primer tratado, De pictura (la versión en latín está dedicada a Federico Gonzaga, marqués de Mantua), que es un tratado de perspectiva donde seguramente Alberti, con sus conocimientos matemáticos, sistematiza a partir de las experiencias del propio Brunelleschi. Este tratado, fechado en 1435, se constituyó en una de las grandes invenciones del Renacimiento y fundamental para el desarrollo de la pintura y la arquitectura. Más tarde escribiría el opúsculo De statua, en 1448, y el tratado de la construcción que denomina De re aedificatoria, en el que trabajará de 1442 a 1452.

Debe destacarse el enorme interés de Alberti en la sistematización de estos nuevos saberes. Antes hemos señalado cómo los incorpora a las artes liberales, donde juega un papel importante su formación universitaria y su conocimiento profundo de varias disciplinas de las letras, las ciencias y las artes. Ordenarlas en tratados es un primer paso para su difusión, pero también es una forma de convertirlas en disciplinas que puedan ser enseñadas a partir de principios y experiencias.

De ellas, será la arquitectura la que le producirá mayor interés, desarrollando un tratado que recoge minuciosamente el proceso constructivo de un edificio desde la elección del lugar y la disposición de este (Libro I, "El trazado"), para pasar luego al estudio de los componentes (Libro II, "Materiales") y 
posteriormente dedicarse al análisis de los procedimientos constructivos (Libro III, "Sobre la obra"). En estos tres primeros capítulos el tratado de Alberti es una suerte de manual de edificación.

Los temas referidos a la ciudad, su disposición y diseño son tratados en el Libro IV ("Sobre las obras de uso público"), para luego ocuparse de las tipologías de los edificios (Libro V, "Sobre las obras de uso restringido"), donde establece diferencias para los palacios, las casas, los templos, etcétera. En referencia a estos capítulos en particular, tiene sentido el comentario que sobre el tratado realiza Verónica Biermann, cuando señala que Alberti sigue el ideal de Cicerón del Perfectus orator (Perfecto orador). Al respecto, señala:

En la antigüedad, la alta formación moral, filosófica y retórica del orador beneficiaba sobremanera a la res publica, la cosa pública, así como a la república en el sentido de una cotidianidad jurídica y política. Sin embargo, el orador de Alberti se veía ante el dilema de ser considerado el Cicerón de su época sin tener la menor posibilidad de ser útil al servicio del bien común, como había sido el caso de su maestro. En respuesta a este dilema, todo hace indicar que Alberti consideraba la arquitectura como una actividad eminentemente política, pues la entendía como conservadora y creadora de cultura capaz de ofrecer de facto seguridad y protección a la comunidad de la ciudad, civitas, lo cual constituye una condición necesaria para su desarrollo cultural y social (Biermann, 2003, p. 24).

Continuando con el libro, los siguientes tres capítulos están orientados a la ornamentación, es decir a la belleza. Como él mismo señala en el capítulo I del Libro VI:

[...] de las tres partes que atañían a la técnica de la construcción en su conjunto, es decir que lo que construyéramos esté de acuerdo con el uso que le vayamos a dar, que sea sumamente sólido, de cara a la mayor duración posible, que esté encaminado a dar impresión de belleza y de placer, una vez tratadas las dos primeras en su totalidad, queda la tercera, la más noble de todas a fuer de absolutamente imprescindible (Alberti, 1550, p. 245).

Es decir, suscribe absolutamente la triada vitruviana de "utilitas, firmitas, venustas" y además dejó para esta última, para aquella que se vincula con Venus, la Diosa de la Belleza, los siguientes tres libros: "De la ornamentación de los edificios religiosos" (LibroVII), "De la ornamentación de los edificios públicos profanos" (Libro VIII) y "De la ornamentación de los edificios privados" (Libro IX). 
El último libro $(\mathrm{X})$ está dedicado al mantenimiento y conservación de los edificios, dando una serie de recomendaciones para tal fin. Hay algunos autores que señalan que el interés de Alberti por el buen estado de los edificios viene a ser el primer atisbo de una genuina preocupación, expresada también en otras partes del tratado por el tema de la conservación y restauración del patrimonio edificado.

Pero retornemos al Libro IX, donde, en el capítulo X, referido al tema de los edificios privados, establece la relación entre arquitectura y arquitecto:

La arquitectura es algo importante y no está al alcance de todos adentrarse en ella. Aquel que se atreva a llamarse "arquitecto" es preciso que esté dotado de una inteligencia excepcional, de una constancia inquebrantable, de amplísimos estudios y de una aquilatada experiencia, y, muy especialmente de un criterio y una prudencia irreprochables y sin tacha. En efecto, el elogio más importante que se puede tener en el arte de la construcción se deriva de saber juzgar adecuadamente qué es lo conveniente. Pues construir deriva de una necesidad; construir convenientemente nace no solo de la necesidad, sino sobre todo de la utilidad; pero construir de modo que den su aprobación los potentados, que no muestren su repulsa las personas sobrias, se derivará únicamente del buen hacer de un artista docto, muy prudente y sumamente juicioso (Alberti,1550, pp. 400-401).

Es también interesante la reflexión que en el mismo capítulo hace sobre la formación del arquitecto, estableciendo claramente la importancia de la experiencia histórica en la adquisición del conocimiento y el ejercicio proyectual:

Por lo demás, debe conducirse en mi opinión como lo hacen quienes se dedican a los estudios literarios. En efecto, ninguno de ellos considerará que ha trabajado lo suficiente la literatura, hasta tanto no haya leído todos los autores de prestigio y conocido a quienes hubieran dejado un escrito en esa materia. De igual manera, en el caso que nos ocupa, cuantas obras hayan recibido la aprobación de la opinión pública, las examinará con muchísima atención, hará dibujos de ellas, registrará sus proporciones, las llevará consigo reproducidas en maquetas hechas a escala; estudiará y reproducirá en su cerebro la ordenación, la colocación, la tipología y las proporciones de cada elemento, sobre todo aquellos elementos de que se han servido quienes ejecutaron obras de mayor envergadura e importancia, personas que hay de suponer que fueron de gran valía, puesto que gestionaron presupuestos tan cuantiosos (Alberti, 1550, p. 401). 
La propuesta albertiana de lo que debe hacer un profesional dedicado a la arquitectura, debe necesariamente inscribirse en el contexto histórico o el espacio-tiempo de esta. El Renacimiento, especialmente lo que se denomina el quattrocento, es decir el siglo $\mathrm{XV}$, es una época prolífica en descubrimientos e inventos, o de inventos y descubrimientos. La brújula, instrumento fundamental de la navegación, fue el invento que posibilitó el descubrimiento de América. La invención del papel y la imprenta permitieron la edición masiva de libros. Se inventa la arquitectura como disciplina artística y científica —matemáticas y dibujo, dijo Alberti-y al arquitecto - en una visión platónica- como su demiurgo o hacedor.

Para ilustrar mejor esta frase, tal vez convenga tomar una cita de otro libro de Alberti: Momus, un texto cómico satírico, que escribiera unos años antes del Tratado de reaedificatora y donde buscó, a través de la ironía, expresar la elevada idea que el autor tenía del arquitecto, especialmente en el pasaje sobre la visita del dios Júpiter a un teatro:

Júpiter [...] (acompañadodelrestodelosdioses, asombradoante unextraordinario teatro) [...] en su interior se consideraba un idiota o un retrasado mental porque al planificar el modelo del mundo futuro, en vez de dirigirse a los constructores de tan excepcional obra, se había dirigido a los filósofos (Alberti, 1443, p. 7).

Después de escribir su tratado, Alberti recibió algunos encargos de arquitectura, como el templo Maletestiano, en Rímini; la iglesia de Sant'Andrea, en Mantua; la fachada de la iglesia de Santa María Novella y el palacio Ruccellai, ambos en Florencia. Por lo tanto, profesó como arquitecto y trató de encontrar coherencia entre sus escritos y sus obras, es decir entre la teoría y la práctica.

Todas las obras mencionadas se consideran, de alguna manera, obras ejemplares y son materia de estudio por la historia y la teoría de la arquitectura. Se trata, evidentemente, de un caso extraño para la época en que la reflexión teórica anticipa al ejercicio práctico, la mayor parte de los tratados sobre arquitectura, recogieron, como el caso de Los cuatro libros de la arquitectura, escritos por Andrea Palladio en el siglo XVI, la experiencia práctica del ejercicio profesional, expresada en textos y dibujos, que permiten entender los edificios y replicarse fácilmente. De alguna manera, se podría considerar también a Alberti como un precursor del racionalismo, anticipándose en un siglo al pensamiento cartesiano del cogito ergo sum. 
Sin embargo, su tratado, como bien lo señala Kruft (1990), “[...] nunca tuvo la fuerza de penetración ni la difusión que a través de los siglos lograron Vitruvio, Serlio y Vignola". Probablemente esto se debió a dos razones: la primera, porque escribió en latín, en consonancia con lo que él esperaba de un arquitecto, un profesional de formación superior y alto nivel cultural, hoy me atrevería a decir universitario. La segunda, en consonancia con la primera, por la ausencia de ilustraciones, que a diferencia de otros tratados fue de uso poco práctico. Pero como bien lo apunta Kruft "[...] como análisis de teoría de la arquitectura la obra de Alberti, quizá sea la más importante aportación que jamás se haya formulado" (s/a, 1990, p. 59).

En su día, el tratado de Alberti consolidó una disciplina y formuló o inventó un perfil profesional, que probablemente fue poco entendido por sus contemporáneos, incluso por los arquitectos que le siguieron en los siglos sucesivos, pero que sirvió al academicismo decimonónico para estructurar las primeras carreras de arquitectura y formar arquitectos en las escuelas superiores de bellas artes primero, y en las universidades después.

Esta visión se proyecta a nuestro tiempo, al mantener el carácter humanístico de nuestra especialidad, y que Alberti expresa en uno de los primeros párrafos de su tratado:

He de explicar qué características debe reunir, en mi opinión, el arquitecto. En efecto, no voy a considerar como tal a un carpintero, a quien tú podrías poner a la altura de los hombres más cualificados de las restantes disciplinas: pues la mano de un obrero le sirve de herramienta al arquitecto.Yo, por mi parte, voy a convenir que el arquitecto será aquel que con un método y un procedimiento determinados y dignos de admiración haya estudiado el modo de proyectar en teoría y también de llevar a cabo en la práctica cualquier obra que, a partir del desplazamiento de los pesos y la unión y el ensamblaje de los cuerpos, se adecue de una forma hermosísima, a las necesidades más propias de los seres humanos. Para hacerlo posible necesita de la intelección y el conocimiento de los temas más excelsos y adecuados.Y de tal índole será el arquitecto (Alberti, 1550,p. 57). 


\section{REFERENCIAS}

Alberti, L. B. (1443-1450). Momus. Cambrige: Harvard College.

Alberti, L. B. (1550 [1991]). De re aedificatoria. Traducción: J. F. Núñez. Madrid:Akal.

Biermann,V. (2003). Leon Battista Alberti (1404-1472). De re adedificatoria libri decem. En: P: Lamers-Schütze (Ed.), Teoría de la arquitectura: del Renacimiento a la actualidad.Traducción: P. Green. Colonia: Taschen.

Kruft,H.W.(1990). Historia de la teoría de la arquitectura. (Vol.1).Traducción: Pablo Diener Ojeda. Madrid: Alianza Editorial. 